Acta Poetica $26(1-2)$

PRIMAVERA-OTOÑO

2005

\title{
Milenios de interacción entre la transmisión oral y la escrita en la India
}

\author{
Juan Miguel de Mora
}

En este artículo se ilustra la interacción entre la oralidad y la escritura sánscrita. El autor da ejemplos de las técnicas para fijar la escritura de los textos sagrados védicos, evitando variantes e interpolaciones durante su oralización. En otros casos, los propios textos escritos contemplan su difusión oral empleando sistemas mnemotécnicos como la versificación para divulgar los conocimientos científicos o gramáticos. Finalmente se comentan algunos textos literarios cuya difusión oral conlleva la recreación.

Oral and written interaction in Sanskrit literature is analyzed in this paper. The author shows how Vedic sacred texts oralisation avoids variants and interpolations. Written texts such as scientific or grammarian treatises include as well mnemonic devices (i e. versification), while the diffusion of other literary texts entails their recreation. 

Acta Poetica 26 (1-2)

PRIMAVERA-OTOÑO

2005

Juan Miguel de Mora

\section{Milenios de interacción entre la transmisión oral y la escrita en la India ${ }^{1}$}

La cultura de la India, como otras del Extremo Oriente, se caracteriza por su larga tradición oral, sin embargo se distingue de otras culturas orales porque desde la escritura está planeada para su divulgación y difusión oral. En los textos gramaticales y científicos se utilizan sistemas mnemotécnicos que permiten su memorización sin interpolaciones; en tanto que los textos religiosos y literarios se oralizan a través de la lectura constante en voz alta para que los oyentes la memoricen y posteriormente la recreen.

Hay testimonios solventes hasta el siglo XIX y principios del $\mathrm{Xx}$ de relatores de etnias distintas e idiomas diferentes que se sabían de memoria el Rig $V_{e d a^{2}}$ en sánscrito y uno que lo

\footnotetext{
${ }^{1}$ Por razones técnicas de impresión en este trabajo no se usarán los signos diacríticos en las palabras sánscritas en alfabeto latino intercaladas en el texto en español.

${ }^{2}$ El Rig es el primero y principal de los cuatro vedas ('veda' significa saber, conocimiento), libros sagrados del hinduismo, que en la más conservadora de las hipótesis, son de mil setecientos cincuenta años antes de nuestra era. Contra la difundida y equivocada creencia de que solamente contiene himnos religiosos, el Rig muestra una variedad de temas que dan una idea acerca de la sociedad de su tiempo, desde la tragedia de un ludópata hasta un irónico poema a la borrachera, pasando por un hombre que tiene miedo a la noche, himnos que ponen en duda al Creador y otros asuntos muy humanos. Se compone de diez libros (mandalas) con mil veintiocho himnos y un total de 10600 estrofas y está escrito en sánscrito arcaico.
} 
recitaba en el sur del subcontinente lo decía exactamente igual a otro que lo declamaba en el norte, hasta en el tono y las pausas.

Aunque el tono específico para recitar el Veda sólo puede aprenderse de oído, no se lograba por casualidad esa uniformidad en el texto, sino porque el Rig Veda es el único libro de la antigüedad que se ha protegido deliberadamente contra las interpolaciones. Esto ocurrió entre los años 800 y 600 antes de nuestra era, cuando fue fijado por escrito, lo que explica que fuese recitado exactamente igual en uno y otro extremo de la India.

Para fijar el texto por escrito se formaron escuelas védicas de las que nos ha llegado mención de tres: Shakala, Baskala y Manduka, pero como no se conserva nada de la última, es costumbre en los estudios sánscritos considerar sólo las dos primeras. Apenas fijado el texto surgió la preocupación por protegerlo de toda posible alteración, cambio, interpolación o pérdida.

Esta visión extraordinaria de la necesidad de proteger el texto —que no tuvieron otras civilizaciones antiguas, coetáneas de la hindú y posteriores - no es sorprendente si se toma en cuenta el grado de adelanto de la India anterior a nuestra era en materia de filología y gramática. Considerando de ineludible importancia que las invocaciones rigvédicas no se malograsen con ningún error, ni semántico ni gramatical, surgieron entonces - y se conservan partes de sus trabajos - gramáticos teológicos que no sólo escribieron en tiempos védicos sino que siguieron existiendo en generaciones posteriores.

Para dar una idea del concepto que tenía la India védica acerca de la palabra transcribiremos algún fragmento del himno 125 del Mandala (capítulo o libro) X del Rig Veda, libro que, según las versiones más conservadoras, sería de mil setecientos cincuenta años antes de nuestra era. Aunque otras opiniones, no menos fundadas, lo sitúan alrededor de cuatro mil años a.n.e. 
Pues bien, en el himno X.125, la Palabra, entre otras cosas, dice:

Soy la que tiene el dominio, la que concentra los bienes

preciosos,

Quien discurre, la primera entre los que gozan del homenaje...

Yo soy quien tensa el arco para Rudra, ique destruya la flecha al enemigo del enunciado!

Yo he creado la contradicción entre los hombres, he penetrado el cielo y la tierra.

Yo soy quien creó al Padre en la cúspide de este mundo.

En el mar, en las aguas está mi origen,

desde allí me propagué por entre todos los seres,

y concierno al mismo cielo con lo que mi palabra vierte. ${ }^{3}$

Esas líneas dan una idea del nivel de abstracción a la que llega el Rig Veda y explica cómo esa cultura era capaz de comprender la importancia de que su texto básico, el Rig $V e d a$, no fuese alterado ni interpolado. Y para fijarlo comenzaron con el pada-patha, que significa "texto de palabras". En la época más antigua de la que se conservan testimonios, el sánscrito se escribió con alfabetos distintos al nagari actual, el kharoshtri y el brahmi, pero se escribía - y así siguió un tiempo con el nagari - con las letras en una fila unida que alcanzaba todo el renglón. Por eso el primer paso para fijar el Rig Veda fue separar las palabras y analizarlas una por una desde todos los puntos de vista posibles.

El siguiente paso fue, precisamente, el krama-patha, que significa "texto de pasos". Se repite cada palabra del pada-patha ligándola con la precedente y con la siguiente. Si las cuatro primeras palabras de un texto fuesen "a", "b", "c" y "d" en el krama-patha se leerían "ab", "bc", "cd". Sigue el jata-

\footnotetext{
${ }^{3}$ Las traducciones del sánscrito del Rig Veda y de los Upanishads son mías.
} 
patha (texto tejido) en el que cada combinación de palabras se menciona tres veces poniendo la segunda en orden invertido: "ab, ba, ab", "bc, cb, bc". Después el ghana-patha (texto complejo) que pone las palabras en el siguiente orden: primera y segunda; segunda y primera; primera, segunda y tercera, tercera, segunda y primera; primera, segunda y tercera; segunda y tercera, tercera y segunda; segunda, tercera y cuarta; cuarta, tercera y segunda; segunda, tercera y cuarta, etcétera.

También se hicieron otros textos compuestos precisando con exactitud todos los cambios requeridos para reconvertir el texto protector al original. Además se elaboraron los índices o anukramanis, obras adicionales que registran el contenido del Rig Veda desde varios puntos de vista e incluyen cálculos sobre el número de versos, de palabras y hasta de sílabas.

Tal vez hubo, a través de siglos y milenios, quienes reescribieron el Veda a su gusto, pero sus escritos jamás fueron tomados en consideración porque sólo las versiones protegidas, prácticamente inalterables, fueron consideradas auténticas. Al descifrarse aparecía el prístino texto del viejo Rig Veda y por eso el relator del extremo norte de la inmensa India coincidía hasta en las pausas con el del extremo sur.

La enseñanza religiosa de textos como los aranyakas, "libros de la selva", llamados así porque estaban reservados a los alumnos admitidos por el gurú ${ }^{4}$ y sólo se enseñaban en la selva, lejos del alcance de oídos ajenos; o la de los upanishad ("doctrinas secretas" es la traducción más difundida, que no corresponde en nada a la palabra upanishad [sentados junto al maestro], sino al contenido de los libros así llamados), ${ }^{5}$ se

\footnotetext{
${ }^{4}$ Es curioso que en la India se diga "guru" y que la Real Academia, al admitir la palabra al castellano, la acentúe en la última "u" modificando radicalmente su sonido.

${ }^{5}$ Los Upanishads son libros de carácter metafísico, en su mayoría, que surgen después de los Vedas y reinterpretan los Vedas. Sin refutarlos (nos recuerdan las graves diferencias entre el Antiguo y el Nuevo Testamento), modifican la religión védica. En aquélla, Dios se muestra en sus manifestaciones naturales, aunque
} 
sujetó en las más de las ocasiones a sistemas mnemotécnicos y estos dos tipos de libros religiosos se escribían ya pensando en facilitar su memorización y su posterior transmisión oral.

Por esa razón muchos de los upanishad están redactados en forma de diálogos, porque es más fácil acordarse de los diálogos entre dos personajes que de un texto árido. Como ejemplo de formas mnemotécnicas en los upanishad tenemos el siguiente diálogo en el Chandogya Upanishad para explicar la sutileza absoluta de la Divinidad:

1. "Tráeme un fruto de este (árbol) nyagrodha". "Aquí está señor". "Pártelo". "Aquí está partido”."¿Qué ves en él?”. "Varios granitos pequeños, señor"; "Bien, parte uno de esos granos". "Aquí está partido, señor”. “QQué ves en él?” "Nada, señor".

2. El padre responde: "Esa esencia sutil que escapa, amigo mío, a nuestra percepción, es por esa esencia sutil que este árbol, por grande que sea, se yergue".

Y también el mismo método es útil para enfrentarse a las leyes implacables del Manava Dharma Shastra (conocido como Leyes de Manu) según las cuales nadie podía estudiar los Vedas sin ser brahmán. Veamos otro diálogo mnemotécnico, éste en el mismo antiquísimo Chandogya Upanishad:

1. Satyakama Jabala dijo un día a Jabala, su madre: "Madre mía, quiero hacer mi noviciado de brahmacharin (estudiante de los Vedas). ¿De qué familia soy?"

2. Ella le contestó: "Hijo mío, no sé de qué linaje eres. Cuando yo era joven, iba y venía por la casa en todos los servicios y entonces te concebí. Ni yo misma sé de quién eres

- también contra lo que se divulga siempre en Occidente- tanto en uno como en otros sólo hay un Dios creador pero con múltiples manifestaciones. En el Veda Dios está fuera. En los Upanishads Dios está dentro del ser humano y no es antropomorfo ni se le puede describir. Dios es todo (pero no "todo es Dios") y el hombre es parte de "eso" (Tat tvan asi). 
hijo. Pero yo me llamo Jabala y tú te llamas Satyakama. Tú eres, por lo tanto, Satyakama Jabala".

3.- Yendo pues con el gurú Haridrumata Gautama le dijo: "Señor, yo quisiera hacer mi noviciado de brahmacharin con usted. ¿Me admite?"

4.- El gurú le contestó: "Veamos amigo, ¿De qué familia eres tú?" Y Satyakama Jabala contestó: "Señor, no sé de qué familia soy. Pregunté a mi madre y ella me dijo: 'En mi juventud, cuando te concebí, yo iba y venía por todos los servicios de la casa y ni yo sé de qué familia eres. Pero yo soy Jabala y tú eres Satyakama'. Por lo tanto yo soy Satyakama Jabala".

5.- Y dijo Gautama: "Sólo un brahmán puede hablar tan sinceramente. Trae leña. Yo te acepto como alumno".

Una obra maestra planeada mnemotécnicamente para ser aprendida de memoria y transmitida por vía oral es la famosa gramática de Panini, a quien se reconoce como el padre de la gramática en el mundo y algunas autoridades en la materia lo consideran el más importante precursor de la lingüística. En sánscrito a la Astadhyayi, la gramática de Panini, se le llama la shabdanushasana, que significa "la enseñanza oral" de Panini.

Consta de ocho secciones subdivididas en cuatro partes cada una y es un tratado de unos cuatro mil versos. La pauta de Panini fue escribir todo en la menor cantidad de palabras que fuera posible. Toda la obra fue planeada para fácil aprendizaje de memoria y transmisión oral y, además de su valor como la gramática más completa y mejor explicada, los expertos la consideran notable como tipo de descripción lingüística. Lingüistas europeos han escrito que "la obra atestigua una tal observación atenta y un sentido de los valores tal que sería en vano buscar algo análogo entre los gramáticos griegos o latinos" (Renou y Filliozat 1953).

O bien: 
Panini tenía por universal y eterna la estructura de la palabra que él ha estudiado. Sin duda el modelo al cual llegó no nos parece tan universal como él debía pensar y queda para nosotros como un modelo sánscrito. Pero la intención de Panini era universal y su ambición le ha llevado mucho más lejos y sobre una vía mucho más científica que sus contemporáneos griegos en el conocimiento del lenguaje. (Filliozat 1988)

Y la gramática de Panini es, con el Rig Veda, el único texto de la India antigua conservado sin cambios ni interpolaciones.

Otro caso importante de auspicios de la memorización para la transmisión oral lo tenemos en la India antigua en materia científica. Aryabhata I, que nació en Pataliputra el año 476 de la era actual, y que afirmó que la Tierra gira sobre su eje y alrededor del Sol, tuvo en eso la misma suerte que Aristarco, de la escuela de Alejandría, que había dicho lo mismo el año 290 a.n.e.: nadie le creyó.

Como un hombre en una embarcación ve a un objeto inmóvil moverse hacia atrás mientras él se mueve hacia delante, de la misma forma lo hacen las estrellas, así mismo lo inmóvil parece moverse diariamente.

Eso decía Aryabhata cuando faltaban mil años para que se conociera la teoría de Copérnico, pero en la India se sabía ya, además de que se aceptaba y que la Tierra es redonda, como una esfera. Lo que no creían era el movimiento. Además, Aryabhata I era un excelente matemático y también encontró el valor de $\pi$ en 3.1416, mucho más preciso que el obtenido por los griegos en aquella época. Y Aryabhata lo escribió en sánscrito de la manera más fácil para su transmisión oral tras haberlo memorizado:

Caturadhikam satam astagunam dvasastis tatha sahasranam I ayutadvayaviskambhasyasanno vrttaparinahah. ${ }^{6}$

${ }^{6}$ Véase nota 1. 
Lo que significa: "cien más cuatro multiplicado por ocho con sesenta y dos en millares, es la circunferencia aproximada de un diámetro de dos veces diez mil". Es decir: "62,832 expresa el valor aproximado de una circunferencia cuyo diámetro se expresase con 20,000". $\pi=62,832 / 20,000=3.1416$.

El eminente sanscritista francés Jean Filliozat decía:

Expresar directamente en un verso sánscrito que la relación de la circunferencia al diámetro vale tres, más mil cuatrocientas dieciséis milésimas hubiera sido demasiado complicado. La aparente vuelta que da Aryabhata para expresar el valor de $\pi$ es, en realidad, una simplificación. (Renou y Filliozat 1953).

El sloka sánscrito de Aryabhata es, como he dicho, fácil de memorizar para quien domina el idioma.

La práctica de escribir pensando en la memorización y su posterior oralización en textos no sagrados da lugar en la India a la interacción entre la transmisión oral y la escrita, donde quien recita puede realizar cambios o modificaciones, cosa normal en un pueblo tan dado a los estudios y análisis literarios como desde hace milenios ha sido la India.

Para probar lo anterior tenemos un texto del siglo IX de nuestra era, debido al poeta Rajasekhara (875-925) y traducido magistralmente del sánscrito al castellano por Óscar Pujol, uno de los más brillantes sanscritistas de habla española. Se llama "El nacimiento del hombre poesía" y cuenta cómo Sarasvati, personificación de las artes, el lenguaje y la música, entre otras cosas, quiso tener un hijo y se dedicó, para conseguirlo, a duros ascetismos. Brahma atendió su ruego y ella dio a luz al poema personificado, es decir, al Hombre Poesía que, apenas nacido se levantó con solemnidad y dijo estas palabras, que en sánscrito forman una estrofa: 
A tus pies, madre, presta obediencia el Hombre Poesía; (soy) ese mundo constituido por el Verbo y que aparece en forma inteligible.

Sarasvati se entusiasma con su hijo y alaba su estrofa diciendo:

Aun siendo la madre del lenguaje me has superado a mí, tu propia madre.

El gran sabio Ushanas recogió al niño y lo llevó a su casa y aquel le transmitió la capacidad de componer en verso y Ushanas dijo:

¡Oh, tú, vaca epigramática!

aunque los vaqueros poetas

día tras día te ordeñen

estás tú siempre repleta. ¡Diosa del conocimiento, acércate a mi vera!

(Rajasekhara 1991)

Demasiado inquieto por diversas causas el hombre poesía se escapó de casa y la esposa de Shiva para detenerlo pensó: ${ }^{7}$

Lo que mejor ata a las personas es el amor. Por lo tanto crearé a una mujer que lo someta.

Y así pensando formó a la Mujer del Hombre Poesía, la Crítica Literaria y le dijo:

Ése que va delante enojado es tu marido. Síguelo y detenlo.

Y a continuación se volvió a los sabios y dijo:

${ }^{7}$ Esta es una versión abreviada del relato. 
¡Oh sabios que han aprendido el arte de la poesía. Celebren con versos la historia de esta pareja, pues así alcanzarán la plenitud poética.

Cosas como ésta se escribían en la India en el siglo x. Pero la literatura hindú llevaba ya unos dos mil años de desarrollo por lo menos. Un clarísimo ejemplo de la interacción entre la versión oral y la escrita la tenemos en Los cincuenta poemas del amor furtivo de Bilhana, que vivió en la segunda mitad del siglo XI. Nació el poeta en Cachemira, en el extremo norte de la India, y entre 1064 y 1068 se trasladó a lo que hoy es Kerala, en el sur, convirtiéndose en el poeta real en la corte del rey Vikramaditya. Los cincuenta poemas del amor furtivo adquirieron una gran popularidad y prácticamente todo el mundo los conocía, por lo que eran muchos quienes lo recitaban aunque se tratase de un texto previamente escrito y reproducido. El resultado es la existencia de gran número de textos manuscritos con divergencias textuales y de los cincuenta poemas sólo siete son comunes a las tres versiones principales, lo que se debe a la acción, consciente o no, de los que los transmitían oralmente por ciudades, pueblos y aldeas, algunos de los cuales reescribían los poemas.

Puesto que el poeta era del norte y vivió en el sur, Óscar Pujol y otros investigadores consideran que los 34 poemas comunes a los manuscritos de Cachemira y del Sur forman el núcleo original del poema.

En la India la literatura no ha sido nunca, en milenios, ni es en la actualidad, privativa de las clases sociales cultivadas. Los poemas famosos y las epopeyas son del dominio público. A diferencia de Grecia donde La Ilíada y La Odisea son sólo referencias nominales para la gran masa de la población, en la India cualquiera, incluso los campesinos, conoce completa la historia de Rama o los hechos del Mahabharata, además de los poemas amorosos que han adquirido fama, que son bastantes. Y aunque Pujol considera, con razón, que M. Krishnamacharya 
exagera al afirmar que actualmente no hay un niño hindú que no se sepa de memoria alguna estrofa de Bilhana, la verdad es que hay mucha gente adulta que sí conoce la obra y memoriza algún que otro dístico o estrofa.

La historia es simple: un poeta joven —contratado por un rey para ser el preceptor de su hija - se enamora de su alumna y es correspondido, y de la teoría amorosa (que en la época debía ser enseñada a las princesas casaderas) ambos pasan a la práctica. Entérase el rey y condena a muerte al poeta que al subir los cincuenta escalones del patíbulo va deteniéndose en cada uno para decir una estrofa en la que proclama y defiende su amor sin soslayar la parte física de la pasión, pero sin caer en el mal gusto. Por ejemplo:



(Bilhana 1995)

En los textos religiosos, quizá el mayor ejemplo de oralización de la India de hoy sea el Ramacharitamanasa de Tulsi Das, más conocido como el Ramayana de Tulsi, que es una versión sacralizada y rehecha del Ramayana de Valmiki, en la cual el rey Rama es convertido en el Dios único y creador.

\footnotetext{
${ }^{8}$ Para tranquilidad de los lectores y lectoras, si los hubiere: en el último momento el poeta de Bilhana es perdonado por el rey y se casa con la princesa.
} 
Tulsi publicó su obra (que escrita en un prácrito llamado avadhi es una obra de arte en cuanto a su estilo y calidad literaria) en 1584, y hoy día en todos los templos del norte de la India hay siempre alguien leyéndola en voz alta ante fieles que la escuchan y van repitiendo cada parte para después repetirla ante otros grupos, familiares o vecinales. Y es muy fácil encontrar en la India personas, hombres y mujeres, que se dedican a recitar de memoria estrofas del Ramayana de Tulsi.

El caso de la India no está reducido a la tradición oral ni lo ha estado desde hace milenios porque el material escrito en sánscrito, sobre todos los temas, en verso y en prosa, en ciencia y en humanidades, es probablemente el más abundante del mundo en cualquier literatura antigua. Más aún, según Louis Renou: "Sin duda ninguna literatura ha tenido ni en el tiempo ni en el espacio, ni por el volumen de sus obras, una extensión parecida a la literatura sánscrita" (Renou 1964).

Y su autoridad para decirlo está fuera de duda pues ha sido uno de los dos o tres sanscritistas más eminentes y documentados del mundo.

\section{REFERENCIAS}

Bilhana, 1995. Los cincuenta poemas del amor furtivo, trad. Oscar Pujol, edición bilingüe, Madrid, Ediciones Hiperion.

Filliozat, Pierre-Sylvain, 1988. Grammaire Sanskrite Pâninéenne, Paris, Picard.

Rajasekhara, 1991. El nacimiento del Hombre-Poesía, versión castellana, intr. y notas de Oscar Pujol, Benarés, Los libros de Benarés.

Renou, Louis, 1964. Anthologie Sanskrite, Paris, Payot.

- y Jean Filliozat, 1953. L'Inde Classique, Hanoi, École Française d'Extrême-Orient. 